\title{
Peripheral Nerves in shiverer $\leftrightarrow$ dystrophic Mouse Chimeras: Evidence that a Non-Schwann Cell Component is Required for Axon Ensheathment in Vivo'
}

\author{
ALAN C. PETERSON \\ Neurosciences Unit, Research Institute, Montreal General Hospital, McGill University, 1650 Cedar Avenue, \\ Montreal, Quebec, Canada H3G 1 A4
}

\begin{abstract}
Peripheral nerves in dystrophic mice express multiple axon ensheathment abnormalities. If an intrinsic deficiency expressed within the Schwann cells themselves were to account for this neuropathy, then such cells, existing in a chimera preparation, would be expected to express the same ensheathment abnormalities, whereas a coexisting population of non-dystrophic Schwann cells should not be similarly affected.

The genotype of myelinated Schwann cells in shlverer $\leftrightarrow$ dystrophic chimera was established with immunocytochemical techniques. Shiverer myelin lacks the P1 component of myelin basic protein (MBP), whereas dystrophic myelin appears to contain normal levels of MBP. No correlation between the ensheathment characteristics of the chimera spinal roots and the genotype of the local Schwann cell population was found; both dystrophic Schwann cell populations expressing normalized ensheathment characteristics and shiverer Schwann cells failing to respond to the local presence of naked axons were observed. These results require that a defective extra Schwann cell component is involved in the pathogenesis of the dystrophic neuropathy. Moreover, the normal realization of that component appears to be a necessary prerequisite for shiverer Schwann cells to achieve full ensheathment competence. Although a definitive identification of the cell type(s) that expresses the dy gene locus has not been achieved in this chimera preparation, the observations are consistent with defective endoneurial fibroblast function.
\end{abstract}

In the mouse, Schwann cell multiplication normally persists throughout the first week of postnatal life (Asbury, 1967; Bray et al., 1977). This process of terminal Schwann cell division occurs within multiple "Schwann cell families," each recognized in nerve crosssections as a bundle of naked axons surrounded by immature uncomitted Schwann cells (Peters and Muir, 1959; Webster et al., 1973; Webster, 1975). Such axon bundles are progressively subdivided by the increasing Schwann cell population such that axons achieve their appropriate numerical relationships with Schwann cells.

Received July 5, 1984; Revised October 1, 1984;

Accepted October 3, 1984

\footnotetext{
'I am grateful to G. Deutch, L. Ohanessian, I. Tretjakoff, and P. Valera for excellent technical assistance, G. Peard for typing the manuscript, and Drs. A. Aguayo and G. Bray for helpful comments. This investigation was supported by a grant from the Muscular Dystrophy Association of Canada.
}

When appropriately innervated, each Schwann cell ceases division and then proceeds to elaborate the particular morphology complementary to the caliber and/or modality of its associated axon(s). In turn, the Schwann cell exerts a local influence on the caliber (Raine et al., 1969; Aguayo et al., 1979a, b) and possibly on the nodal specialization of its innervating axon(s) (Bostock and Sears, 1978; Aguayo et al., 1979a, b; Bray et al., 1981). This exquisite developmental interaction could only be realized if both the axons and Schwann cells were competent to provide, recognize, and respond to the appropriate molecular signals constituting cell-cell communication. Thus, for an inherited neuropathy in which Schwann cells fail to achieve a normal phenotype, either a deficiency intrinsic to the Schwann cell itself or a failure of the appropriate developmental signals to reach an otherwise competent Schwann cell population could equally describe the underlying pathogenetic mechanism

For the Trembler, Quaking, and shiverer mutants, primary glial abnormalities appear to be entirely responsible for the neuropathies observed (Ayers and Anderson, 1973, 1976; Low, 1977; Suzuki and Zagoren, 1977; Aguayo et al., 1979a; Cornbrooks et al., 1980; Chernoff, 1981; Peterson and Marler, 1983; Roach et al., 1983). However, in sharp contrast to mutants in which the process of myelinogenesis per se is perturbed, the pathogenesis of the neurological deficiencies expressed within the dystrophic mouse $(d y)$ (Michelson et al., 1955) has defied comparable definition. In association with a progressive muscle disease (Butler and Cosmos, 1977), such mice reveal multiple, seemingly distinct, Schwann cell abnormalities. Discrete locations in the PNS of dystrophic mice are populated with Schwann cells that fail altogether to separate and ensheath axons during primary development (Bradley and Jenkison, $1973,1975)$. These susceptible regions include the longer spinal roots and cranial nerves and, to a lesser extent, certain locations within the more peripheral mixed nerves (Jaros and Bradley, 1979). Reminiscent of early primary development, these affected sites reveal closely apposed "naked" axon bundles typically delineated by undifferentiated, presumptive, Schwann cells. In addition, relatively sublle ensheathment defects are expressed elsewhere (Jaros and Bradley, 1979); the nodal regions of otherwise typically ensheathed axons are frequently elongated, and the basal laminas on both myelinated and unmyelinated Schwann cells express multiple small gaps such that approximately $29 \%$ of their plasma membranes appears to be exposed directly to the extracellular fluid (Madrid et al., 1975). Thus, the neurological deficiencies in dystrophic mice present as a localized and persistent failure in one of the earliest interactions between Schwann cells and axons (axon separation and ensheathment) and as morphologically subtle perturbations, including one of the latest manifestations of individual Schwann cell maturation (basal lamina formation). Moreover, the localized ensheathment disorder and/or the generalized basal lamina deficiencies associated with Schwann cells in dystrophic mice can be 
significantly altered in various tissue culture, transplant, regeneration, and chimera preparations (Stirling, 1975; Bray et al., 1983; Cornbrooks et al., 1983; Peterson and Bray, 1984b), indicating that some influence originating outside the Schwann cell itself may have a significant and, possibly, primary role in the pathogenesis of this disease.

To further assess the role of the dystrophic Schwann cell in the in vivo pathogenesis of this neuropathy, a chimera preparation derived from dystrophic and non-dystrophic cells has been exploited. If dystrophic Schwann cells are intrinsically defective, they should similarly fail to ensheath axons in the nerves of these chimeras, whereas normal Schwann cells should be unaffected and potentially compensate for the dystrophic Schwann cell deficiency. Alternatively, if the dystrophic neuropathy results as a secondary response to an extra Schwann cell defect, no such correlation should be observed.

A reliable means of identifying the genotype of the Schwann cells present in such chimera nerves was provided by incorporating shiverer cells as the non-dystrophic component of these chimeras. The P1 component of myelin basic protein (P1 MBP) is not detectable in shiverer Schwann cells (Ganser and Kirschner, 1979; Kirschner and Ganser, 1980; Roach et al., 1983), and although shiverer Schwann cells do express minor morphological deficiencies (Rosenbluth, 1980), particularly in myelin thickness (Peterson and Bray, 1984a, b), they appear to develop (Peterson and Marler, 1983) and regenerate (R. L. Sidman, personal communication) normally. The myelin synthesized by dystrophic Schwann cells contains normal levels of P1 MPB (this report). Therefore, immunocytochemical detection of P1 MBP served to identify the genotype of all myelinated Schwann cells existing in sections of these chimera nerves. Light or electron microscopy of adjacent sections permitted a direct assessment of the nerve morphology realized relative to the proportions and particular locations of dystrophic and shiverer Schwann cells within each nerve.

\section{Materials and Methods}

\section{Chimera preparation}

Mice. The shiverer colony was founded by shil+ mice generously provided by Dr. T. Bird, Veterans Administration Hospital, Seattle, Washington. These mice were derived from multiple crosses between the SWV strain, in which the shiverer mutation occurred, and the ICR strain. Since 1979, this stock has been maintained as a closed colony in the animal facility of the Montreal General Hospital Research Institute. The shi allele is maintained by heterozygote (shi/+) matings and by shi/ $+\times$ shi/shi matings (usually successful if the male is approximately 3 months old).

Dystrophic embryos $\left(d y^{2 J} / d y^{2 J}\right)$ were obtained from timed matings between $d y^{2 J} / d y^{2,}$ mice of the C57BL/6J strain. Shiverer embryos were obtained from timed matings between shi/shi females and shi/+ males; of the resulting embryos, one half were expected to be shi/shi homozygotes and the remainder were expected to be shilt. Chimeras were produced by aggregating pairs of eight-cell embryos in vitro, culturing these aggregates for 24 $\mathrm{hr}$, during which time they differentiated into blastocysts, and subsequently transplanting the chimera blastocysts to the uterus of a pseudopregnant female to complete in utero development (Mullen and Whitten, 1971). To identify $d y^{2 J} / d y^{2\lrcorner} \leftrightarrow$ shi/shi chimeras, we relied upon the total absence of immunocytochemically detectible P1 MBP in a portion of the myelinated Schwann cells present in the mature chimera nerves. In total, seven chimeras were produced. One with clinical symptoms of the shiverer syndrome died naturally and was not analyzed. On the basis of immunocytochemistry (see "Results"), three were determined to be shi/shi $\leftrightarrow d y^{2 J} / d y^{2 s}$ and were designated $\mathrm{A}, \mathrm{B}$, and $\mathrm{C}$; the remaining three were identified as shil+ $\leftrightarrow$ $d y^{2 J} / d y^{2 J}$. All seven chimeras demonstrated both coat color mosaicism and mosaicism within ear punch biopsies detected by GPI-1 isozyme analysis (Peterson et al., 1978).

\section{Sample preparation}

Chimeras. At 4 months (chimera C) and at 12 months (chimeras A and B) of age, the chimeras were anesthetized with sodium pentobarbital and systemically perfused with $1.5 \%$ glutaraldehyde and $1 \%$ paraformaldehyde in $0.1 \mathrm{M}$ phosphate buffer $(\mathrm{pH} 7.4)$. Spinal roots and mixed nerves were recovered within $1 \mathrm{hr}$ and immersed in cold $\left(4^{\circ} \mathrm{C}\right) 2 \%$ osium tetroxide in a $0.1 \mathrm{M}$ phosphate buffer $(\mathrm{pH} 7.6)$ for an additional 18 to $24 \mathrm{hr}$. Each nerve was then cut into segments 5 to $10 \mathrm{~mm}$ long followed by routine embedding in epoxy resin (Epon)

Control mice. Peripheral nerves from mature C57BL/6J $+1+$, shi/shi, C57BL/6J $d y^{2 J} / d y^{2 J}$, and a 1-year-old shi/shi $\leftrightarrow$ C57BL/6 $+/+$ chimera (Peterson and Marler, 1983) were obtained and processed in the identical manner.

\section{Immunocytochemical procedures}

Antiserum. The antiserum used throughout this study was raised in rabbits against the 18,500-dalton species of bovine CNS MBP and cross-reacts with all four bovine CNS basic protein species as well as the 18,500-dalton MBP of rodent PNS. It was generously provided by Dr. P. Braun, McGill University.

Immunocytochemistry. For P1 immunocytochemistry the general procedures outlined by others (Trapp et al., 1981) were followed. Briefly, $2-\mu \mathrm{m}$ thick sections were transferred to ethanol-washed coverslips and dried, first at room temperature and subsequently at $60^{\circ} \mathrm{C}$ for a minimum of $4 \mathrm{hr}$. To prepare the sections for immunocytochemistry, the Epon was removed by immersing the coverslips in sodium ethoxide diluted 1:3 with absolute ethanol, for 10 to $30 \mathrm{~min}$. The coverslips were then washed in absolute ethanol four times for $2 \mathrm{~min}$, immersed in $0.1 \% \mathrm{H}_{2} \mathrm{O}_{2}$ for $5 \mathrm{~min}$ at room temperature, and washed three times for $10 \mathrm{~min}$ with $0.5 \mathrm{M}$ Tris- $\mathrm{HCl}, \mathrm{pH}$ 7.6. The coverslips were then drained, and each section was covered first with $100 \mu \mathrm{l}$ of $3 \%$ normal goat serum (NGS) (Sternberger Meyer) in $0.5 \mathrm{M}$ Tris- $\mathrm{HCl}, \mathrm{pH} 7.6$, and incubated for $30 \mathrm{~min}$ at room temperature followed by $50 \mu \mathrm{l}$ of $\mathrm{P} 1$ antiserum (1:1000 dilution, $0.5 \mathrm{M}$ Tris- $\mathrm{HCl}, \mathrm{pH} 7.6$, containing $1 \%$ NGS) and then incubated in a humidified chamber at $4^{\circ} \mathrm{C}$ overnight. Peroxidase-antiperoxidase immunocytochemical detection of bound rabbit antibody was then

\section{TOLUIDINE BLUE}

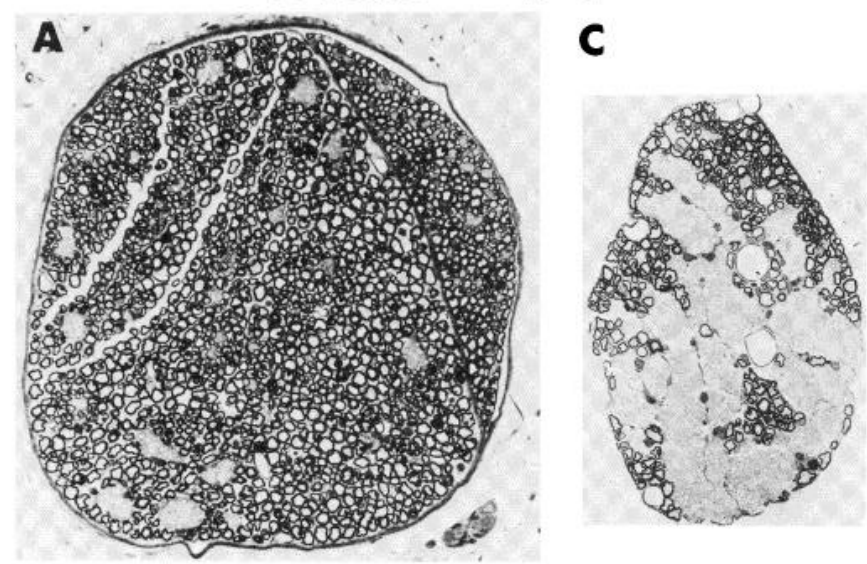

\section{PI IMMUNOCYTOCHEMISTRY}
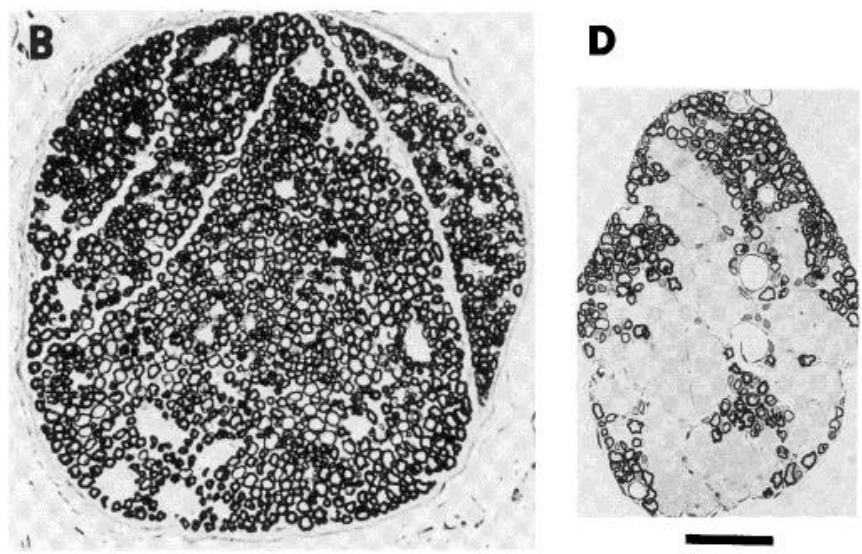

Figure 1. Peripheral nerves from a C57BL/6J $d y^{2 J} / d y^{2 J}$ mouse. Adjacent cross-sections reveal that all myelin identified in a sciatic nerve $(A$ and $B)$ and an affected L3D spinal root binds antisera with specificity for MBP P1 $(C$ and $D)$. Calibration bar $=100 \mu \mathrm{m}$ for $A$ and $B$, and $73 \mu \mathrm{m}$ for $C$ and $D$. 

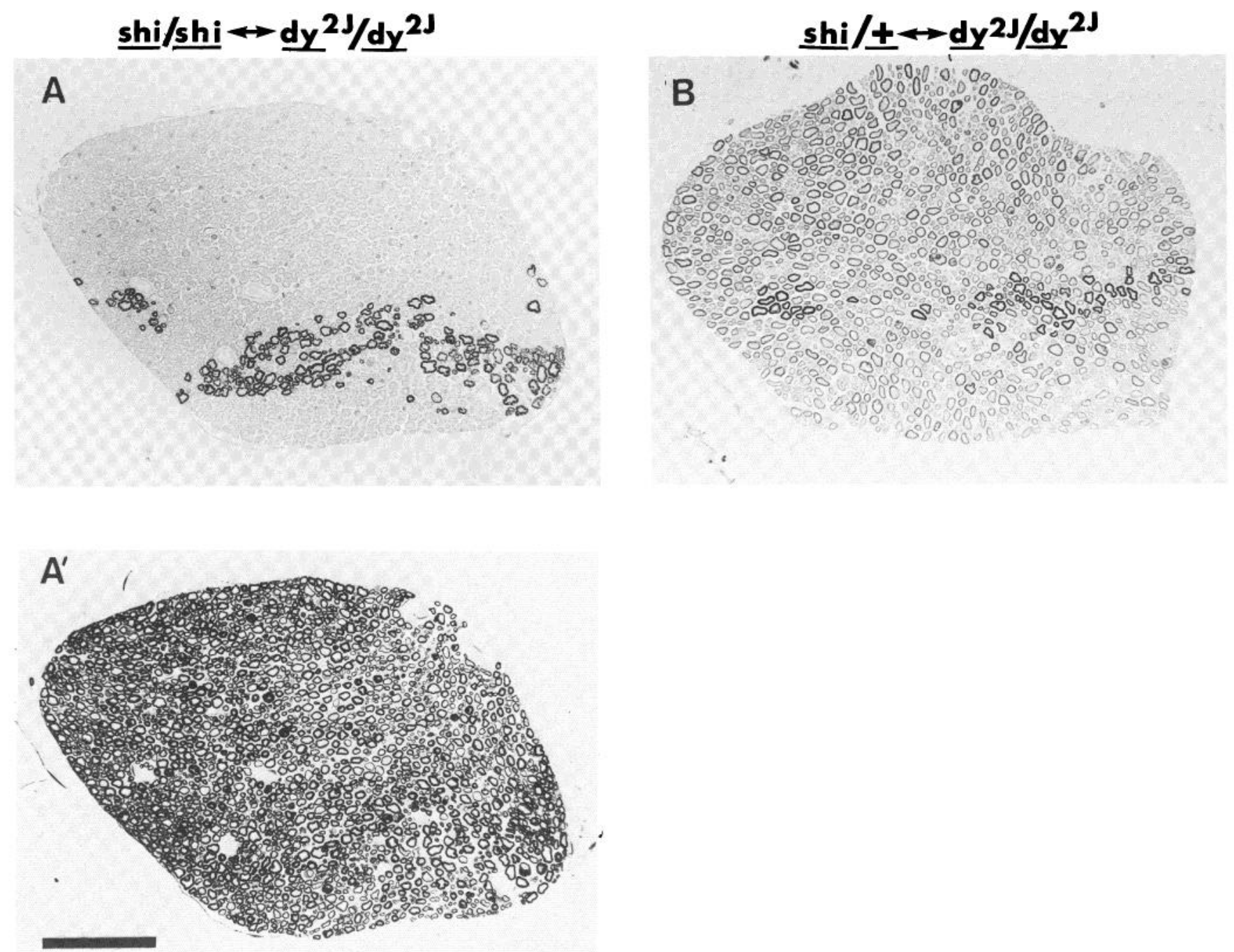

Figure 2. $\mathrm{P} 1$ immunocytochemistry of chimera spinal roots. $A$, Left $\mathrm{L} 4 \mathrm{D}$ spinal root of chimera $\mathrm{B}$ reveals $\mathrm{P} 1$-positive $\left(d y^{2 J} / d y^{2 J}\right)$ and $\mathrm{P} 1$-negative $($ shi/shi) myelin sheaths identifying a chimera of shi/shi $\leftrightarrow d y^{2 J} / d y^{2 J}$ genotype. $A^{\prime}$, Toluidine blue-stained preparation of an adjacent section. $B$, In the left $L 4 D$ spinal root of another chimera, all myelin is P1 positive but the presence of myelin with an intermediate immunocytochemical reaction identifies the genotype of this chimera as shil+ $\leftrightarrow d y^{2 J} / d y^{2 j}$. Calibration bar $=100 \mu \mathrm{m}$.

performed by standard procedures (Sternberger et al., 1970), and the sections were subsequently viewed with a Leitz Orthoplan microscope.

In all cases, adjacent $0.5-\mu \mathrm{m}$ sections were obtained and stained directly with toluidine blue for correlative histological analysis by light microscopy. In certain circumstances adjacent ultrathin sections were obtained for correlative ultrastructural analysis. Ultrastructural preservation was considered adequate, although the fixation protocol was optimized for immunocytochemistry.

\section{Results}

Immunocytochemical control experiments. Peripheral myelin in shiverer mice reveals no observable reaction product when processed with the immunocytochemistry techniques described. The myelin in genotypically normal mice stains intensely and uniformly (see Peterson and Marler, 1983).

P1 immunocytochemistry revealed intensely stained myelin sheaths in the PNS of dystrophic mice. Myelinated Schwann cells within either normally ensheathed nerves (Fig. 1, $A$ and $B$ ) or immediately adjacent to naked axon bundles within affected spinal roots (Fig. 1, C and D) are consistently P1 positive. However, relatively rare hypomyelinated fibers in dystrophic spinal roots typically revealed less reaction product than was observed in normally myelinated fibers, a result most likely directly related to the thinner myelin in such fibers. Throughout the remainder of the PNS of dystrophic mice, the intensity of the P1 immunocytochemical reac- tion was indistinguishable from that observed when nerves from genotypically normal mice are similarly processed. This result indicates that P1 biosynthesis is not perturbed within genotypically dystrophic Schwann cells, and, therefore, a fundamental prerequisite of applying P1 immunocytochemistry as the genotype marking system was fulfilled.

Chimera genotype. The P1 expression in nerves from the six potential shi/shi $\leftrightarrow d y^{2 J} / d y^{2 J}$ chimeras available for this study was examined to define the genotype of cells derived from shi/shi $\times$ shil+ matings. In three chimeras designated $A, B$, and $C$, both P1 positive $\left(d y^{2 J} / d y^{2 J}\right)$ and $\mathrm{P} 1$ negative (shi/shi) myelin sheaths were observed (e.g., Fig. $2 A$ ). In the remaining three chimeras, although all myelin was P1 positive, there were two distinguishable classes of myelin sheaths; intensely labeled myelin typical of dystrophic nerves and myelin revealing an intensity of staining approximately intermediate between shiverer (no staining) and that observed in dystrophic myelin (e.g., Fig. 2B), and such weakly stained cells were presumed to be shilt. The further analysis of the presumed shilt $\leftrightarrow d y^{2 j} /$ $d y^{2 J}$ chimeras was limited to histological preparations avoiding any possibility of ambiguity in Schwann cell genotype assessment.

The proportion of shi/shi $\leftrightarrow d y^{2 J} / d y^{2 J}$ and shi/t $\leftrightarrow d y^{2 J} / d y^{2 J}$ chimeras recovered fits the predicted ratio of shi/shi and shilt chimeras that should be derived from embryos obtained from shil 


\section{shi/shi $\longrightarrow d y^{2 J} / d y^{2 J}(A)$}

\section{LL4V}

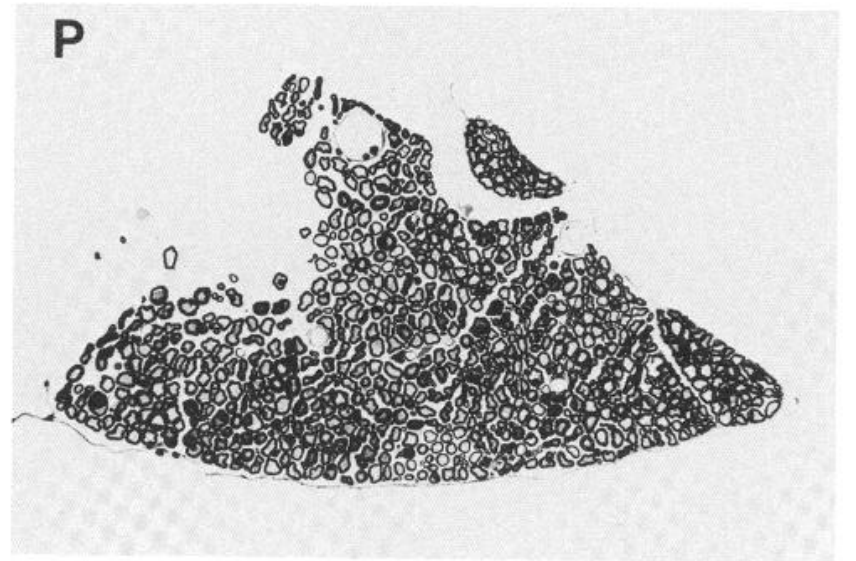

\section{$3.25 \mathrm{~mm}$}

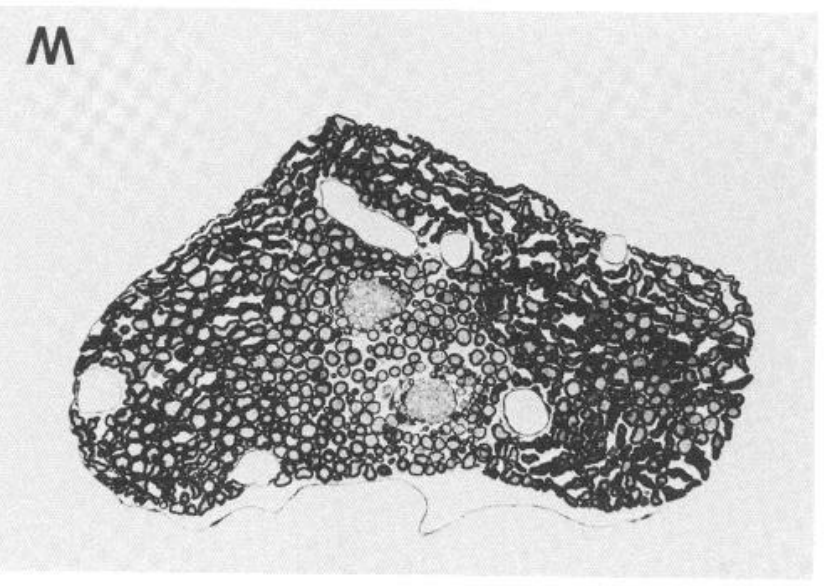

\section{$6.35 \mathrm{~mm}$}

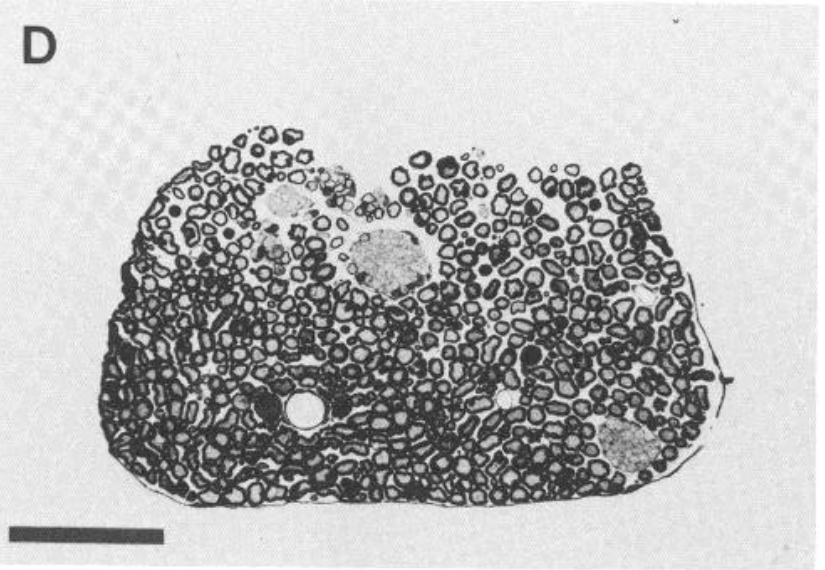

RL4V

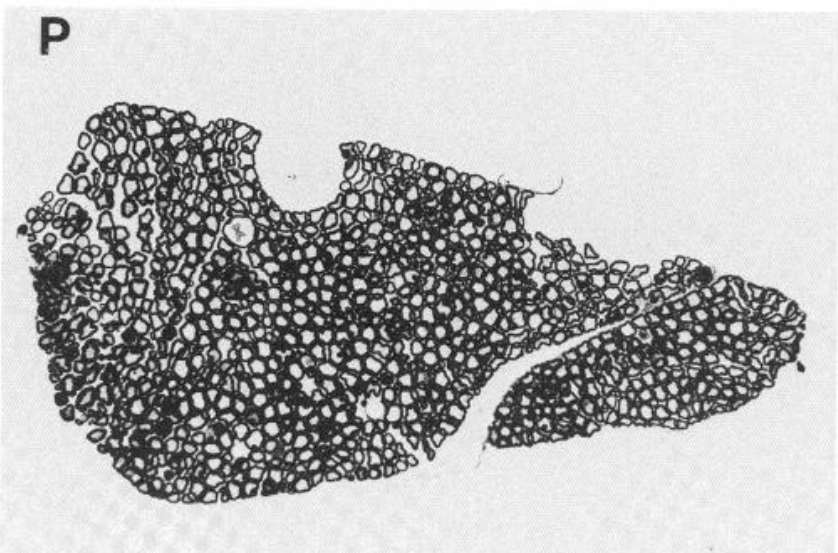

$3.70 \mathrm{~mm}$

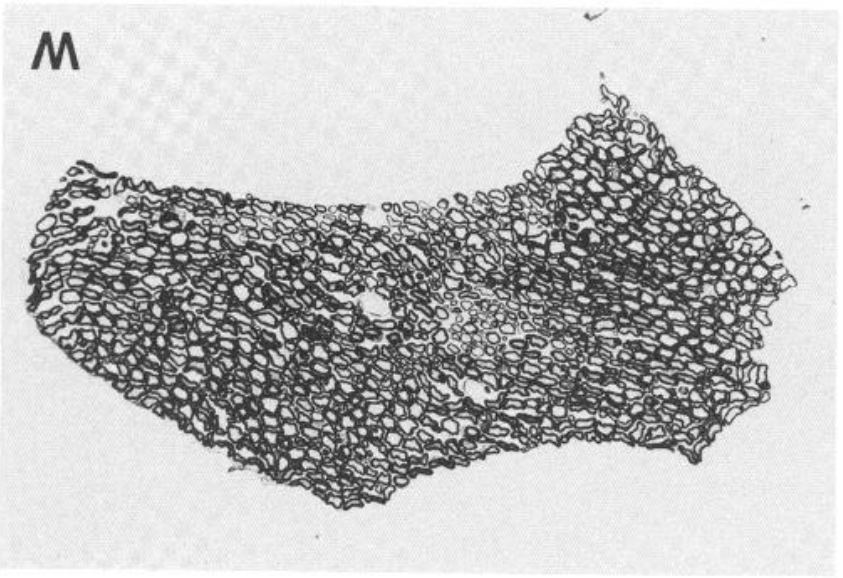

$6.70 \mathrm{~mm}$

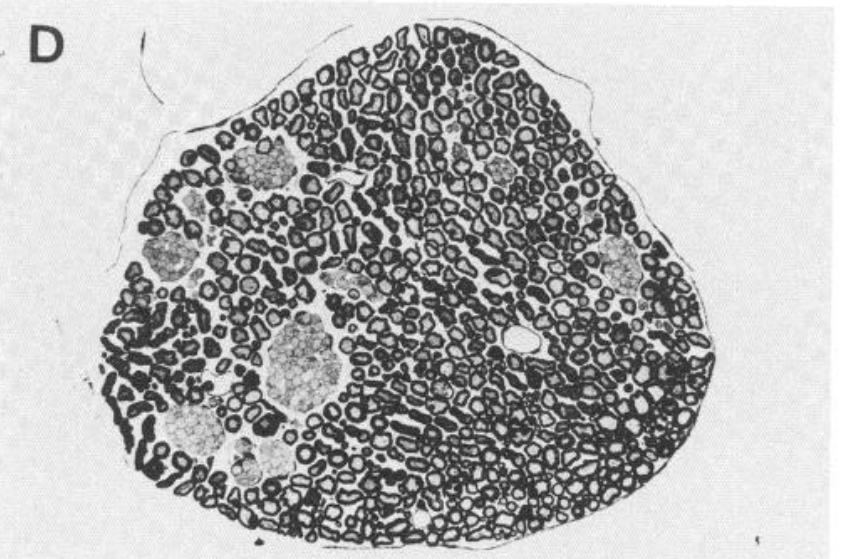

Figure 3. The left $(L)$ and right $(R) L 4 V$ roots of chimera $A$ contain small bundles of naked axons. In the most proximal level $(P)$ all axons were ensheathed in both. The middle $(M)$ and distal $(D)$ levels of the left $L 4 \mathrm{~V}$ were affected, whereas only the most distal level of the right $L 4 V$ was similarly affected. Total length of the left $L 4 V$ was $10.2 \mathrm{~mm}$ and of the right $L 4 \mathrm{~V}$ was $10.1 \mathrm{~mm}$. Numbers indicate distance in millimeters from the spinal cord. Calibration bar $=100$ $\mu \mathrm{m}$. 

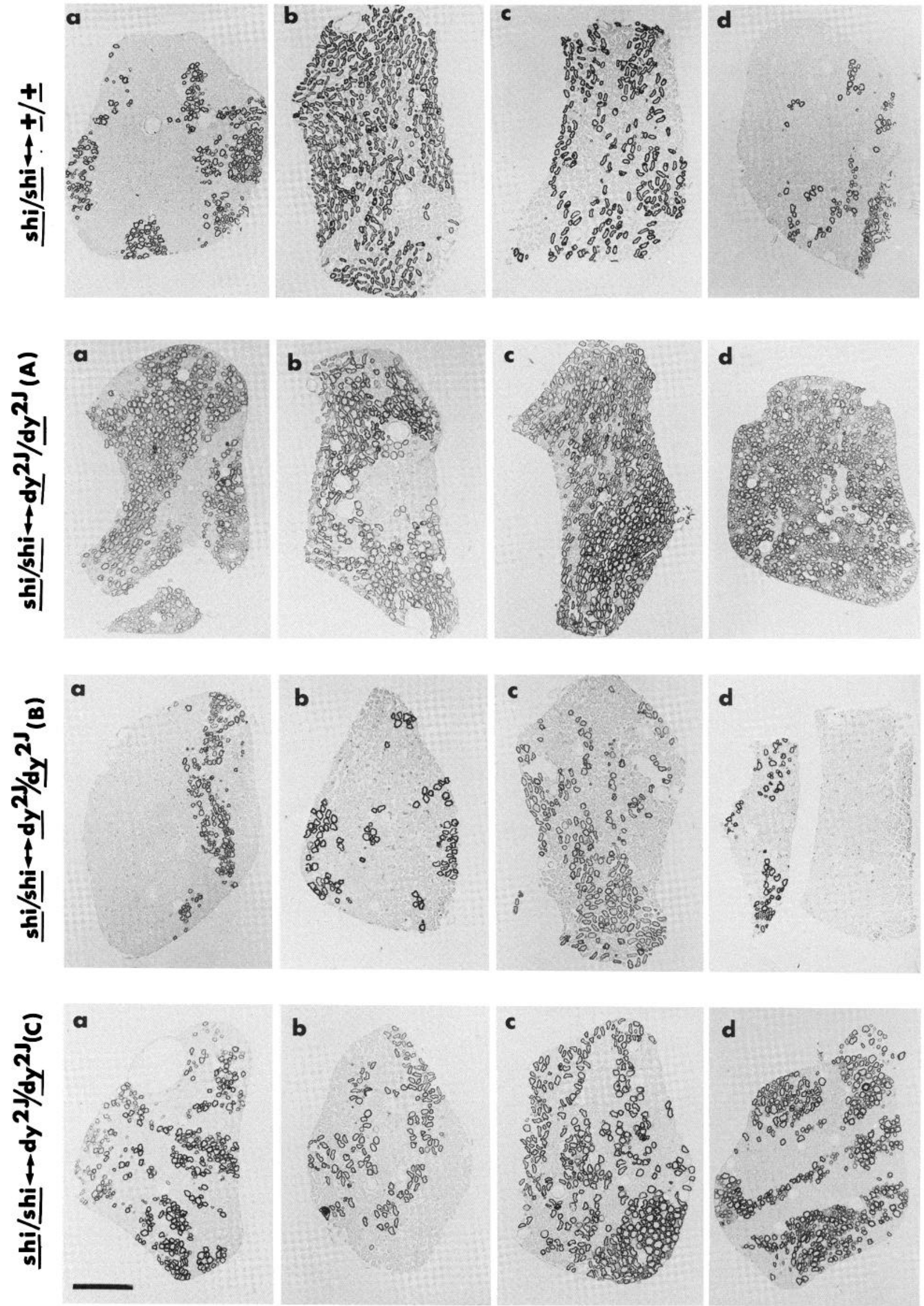

Figure 4. The distribution of shi/shi and $d y^{2 J} / d y^{2 J}$ Schwann cells at the midroot level of the left $L 4 D(a)$ and $L 4 V(b)$ and the right $L 4 V(c)$ and $L 4 D(d)$ of the control chimera and the three shi/shi $\leftrightarrow d y^{2 J} / d y^{2 J}$ chimeras (A, B, and C). Calibration bar $=100 \mu \mathrm{m}$. 
TABLE I

Proportions of shiverer and normal (control chimera) and shiverer and dystrophic (chimeras A, B, and C) Schwann cells existing in cross-sections obtained from the middle (i.e., the second block face (2)) of both dorsal and ventral spinal roots at $L 3$ to $L 6$

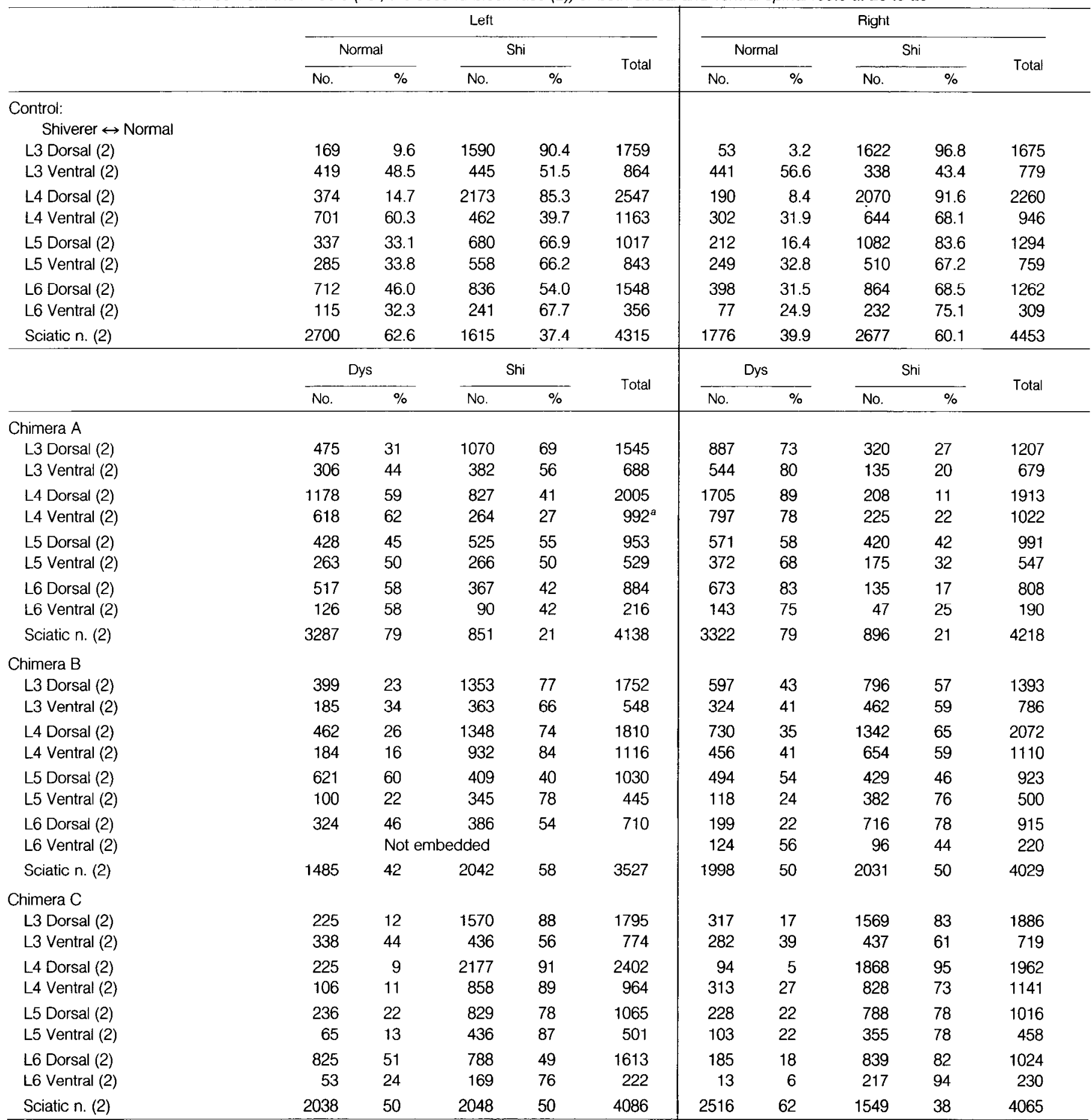

a This total includes $110(11 \%)$ uncnsheathed axons.

shi $\times$ shil+ matings; i.e., $50 \%$ shi/shi: $50 \%$ shil+ expected versus 4 of 7 shi/shi:3 of 7 shilt observed. The chimera exhibiting the shiverer clinical phenotype prior to death was classified as shi/shi $\leftrightarrow d y^{2 J} / d y^{2 J}$; the remaining six chimeras exhibited a generally normal clinical phenotype. Subtle abnormalities were observed in the posture assumed by the hindlimbs of chimera A when it was suspended by the tail.

Morphology of spinal roots: Light microscopy. Cross-sections from the proximal, middle, and distal segments of both dorsal and ventral spinal roots (L3, L4, L5, and L6) were prepared from all six chimeras and examined for the presence of naked axons. Bundles of naked axons were observed in only 2 of the 96 roots examined (the left and right $L 4$ ventral (L $4 \mathrm{~V}$ ) roots of chimera $A$; Fig. 3 ). The remaining 94 roots generally expressed a normal morphology, although, rarely, both isolated axons, apparently without appropriate Schwann cell ensheathment, and a variety of subtle myelin abnormalities were observed. Multiple levels of the affected $L 4 \mathrm{~V}$ roots were examined to determine the longitudinal extent of these naked axons; in both, naked axons were observed at the most distal levels. whereas only the left L4V was affected at the midroot level. 


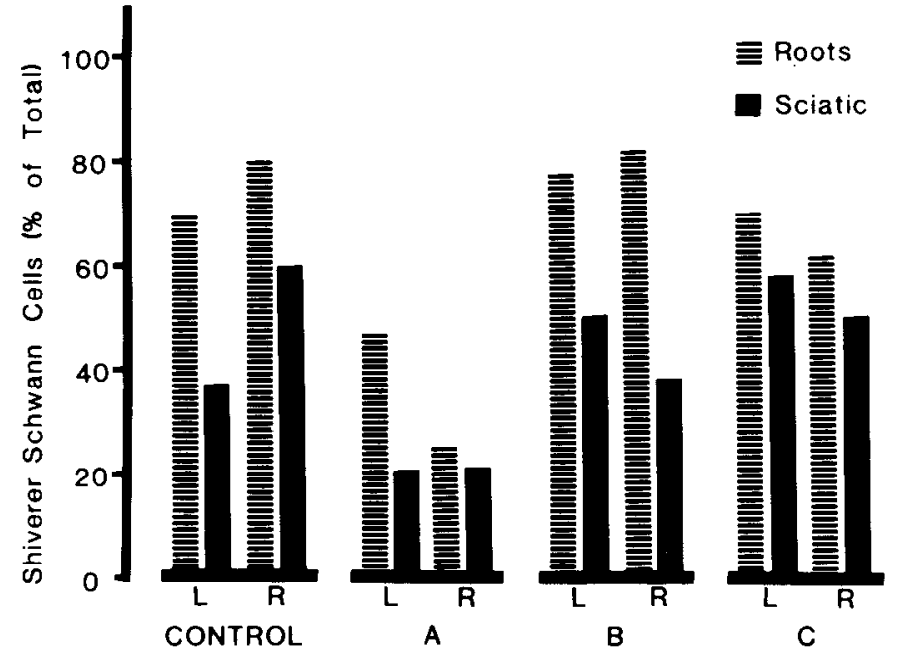

Figure 5. Comparisons of total Schwann cell populations in the left $(L)$ and right $(R)$ spinal roots (L3 to L6) and sciatic nerves of shi/shi $\leftrightarrow+1+$ control and shi/shi $\leftrightarrow d y^{2 s} / d y^{2 s}$ chimeras A, B, and C. If dystrophic Schwann cells fail to populate the spinal roots of shi/shi $\leftrightarrow d y^{2 J} / d y^{2 J}$ chimera, such roots should contain a majority of shiverer Schwann cells. Sciatic nerves should not be subject to the same selection pressure. Although every chimera (including the control) has a relatively greater proportion of shiverer Schwann cells in spinal roots than in sciatic nerves, no consistent selective advantage of shiverer Schwann cells in spinal roots is revealed. In particular, the left spinal root samples of chimera $A$ were composed of an equal proportion of both Schwann cell genotypes, whereas the right spinal root samples were dominated by dystrophic Schwann cells.

Genotype of Schwann cells in normal and affected chimera roots. The general amelioration of ensheathment defects could be accounted for by a simple numerical compensation conferred directly by the coexisting shiverer Schwann cells. If shiverer Schwann cells expressed a relative developmental advantage, or if they were secondarily recruited to ensheath axons in nerves where dystrophic Schwann cells had failed during primary development, the normally ensheathed roots in these chimeras should contain a predominance of shiverer Schwann cells. Therefore, the relative proportions of shiverer and dystrophic cells existing in all spinal roots at L3 to L6 levels were estimated by counting shiverer (P1 negative) and dystrophic (P1 positive) Schwann cells present in cross-sections obtained from the middle of each root. Examples of the immunocytochemical preparations of $L 4$ roots are presented in Figure 4 . The quantitative results obtained for spinal roots and sciatic nerves from the three shi/shi $\leftrightarrow d y^{2 J} / d y^{2 . J}$ chimeras and the shi/shi $\leftrightarrow+/+$ control chimera are presented in Table I.

Comparisons of the proportion of the Schwann cell population composed of shiverer cells in roots versus sciatic nerves is presented in Figure 5. Within each chimera a relative deficiency of dystrophic Schwann cells is observed in the spinal root samples. However, this apparent shiverer advantage does not appear to result from a failure of the dystrophic Schwann cell populations, as a similar shiverer Schwann cell advantage was also observed in the shi/shi $\leftrightarrow+/+$ control chimera. Moreover, certain unaffected roots within the shil shi $\leftrightarrow d y^{2 J} / d y^{2 l}$ chimera samples contained a marked preponderance (highest, $89 \%$ ) of dystrophic Schwann cells, and in some chimeras, differences between the equivalent left and right samples were as large as the differences observed between the sciatic and root samples (e.g., control chimera, chimera $A$, and chimera $C$ ). Thus, no consistent deficiency in the relative ability of dystrophic Schwann cells to populate and appropriately ensheath spinal roots in these chimeras is detected by this quantitative analysis.

Every chimera spinal root analyzed was found to contain Schwann cells of both genotypes at the midroot level. (The right L4 dorsal (L4D) root from chimera B was composed of two branches, and in this unique case, only shiverer Schwann cells were present in one branch (Fig. 4)). If a developmental failure affecting only dystrophic Schwann cells had occurred, it should have been revealed in the spatial organization of the shiverer and dystrophic Schwann cell populations coexisting in these chimera spinal roots. A visual examination of the mosaic patterns expressed in the middle of $L 4 \mathrm{~V}$ and $L 4 D$ roots (that typically express the maximum proportion of unensheathed axons in dystrophic mice) did not reveal any exceptional mosaic patterns indicative of such a compensation (Fig. 4). Although the mosaic patterns are highly variable and apparently complex, no indication of larger than normal groups of shiverer Schwann cells is discernible. Rather, roots in which only small patches of shiverer Schwann cells are present (e.g., the right L4V and $L 4 D$ roots of chimera $A$ ), roots with equivalent proportions and mixtures of the two cell lines (e.g., right $L 4 V$, chimera $C$ ), and roots in which only small clusters of dystrophic Schwann cells are present (e.g., left L4D, chimera B) were observed. This apparent variability is also represented in the roots from the control chimera, further indicating that no special developmental compensation by the shiverer cell line had occurred in the shi/shi $\leftrightarrow d y^{2 J} / d y^{2 J}$ chimera.

Spatial distribution of dystrophic and shiverer Schwann cells relative to naked axons. The quantitative results presented above indicated that the relative proportions of dystrophic and shiverer Schwann cells in chimera roots could not account for the generally normal development observed. However, it remained possible that, within the two affected roots, dystrophic Schwann cells were distributed in such a way that shiverer Schwann cells were physically isolated from the naked axons. To determine whether such a unique spatial relationship existed within these roots, more detailed examination of the cross-sectional and longitudinal relationships between naked axons and the adjacent Schwann cell population was performed. Cross-sections of both affected roots revealed numerous clear examples of shiverer Schwann cells situated in relative proximity to naked axon groups (e.g., Fig. 6). Thus, no evidence of a unique spatial distribution of dystrophic Schwann cells in the lateral dimension appeared to account for the presence of naked axons in this analysis. To determine the longitudinal relationships existing between naked axon segments and the genotype of Schwann cells at the first heminode, a reconstruction obtained from skip serial sections was prepared. Two hundred micrometers of the left I $4 \mathrm{~V}$ root were serially sectioned and the ensheathment characteristics of 300 axons (outlined in Fig. 6) along this length were determined. The results are summarized in Figure 7 and Table II. Both shiverer and dystrophic Schwann cells are found very close to the longitudinal terminations of unensheathed portions of naked axons. Within the cross-sections containing many of these heminodes, additional cytoplasmic processes were discernible and, in some cases, such additional processes, completely ensheathing or partially surrounding the axon, persisted for several micrometers from the junction

\footnotetext{
Figure 6. Schwann cell genotype on myelinated fibers adjacent to naked axons in the left L4V root of chimera $A$. Toluidine blue $(A)$ and $P 1$ immunocytochemistry $(B)$ of adjacent section reveals both shiverer and dystrophic Schwann cells in close proximity to naked axons. $C$ shows detail of naked axon bundles; the square identifies the area represented in the electron micrograph montage $(E)$. $D$, Detail of immunocytochemical preparation. The outlined area contains the 300 axons reconstructed from skip serial sections obtained from the $200 \mu \mathrm{m}$ distal in the root. $E$, Electron micrograph montage revealing the typical appearance of naked axons (left side) as expressed in dystrophic mice. In addition, small groups of naked axons partially ensheathed by cytoplasmic processes and isolated axons lacking ensheathment, as well as typically ensheathed fibers, are observed. Those fibers ensheathed by dystrophic Schwann cells are labeled dy; all other myelin is derived from shiverer Schwann cells. The relative hypomyelination observed on fibers ensheathed by shiverer Schwann cells is typical of the shiverer phenotype (myelinated fibers in the spinal roots of shiverer mice and myelinated fibers ensheathed by shiverer Schwann cells in shiverer $\leftrightarrow$ normal chimera are relatively hypomyelinated).
} 

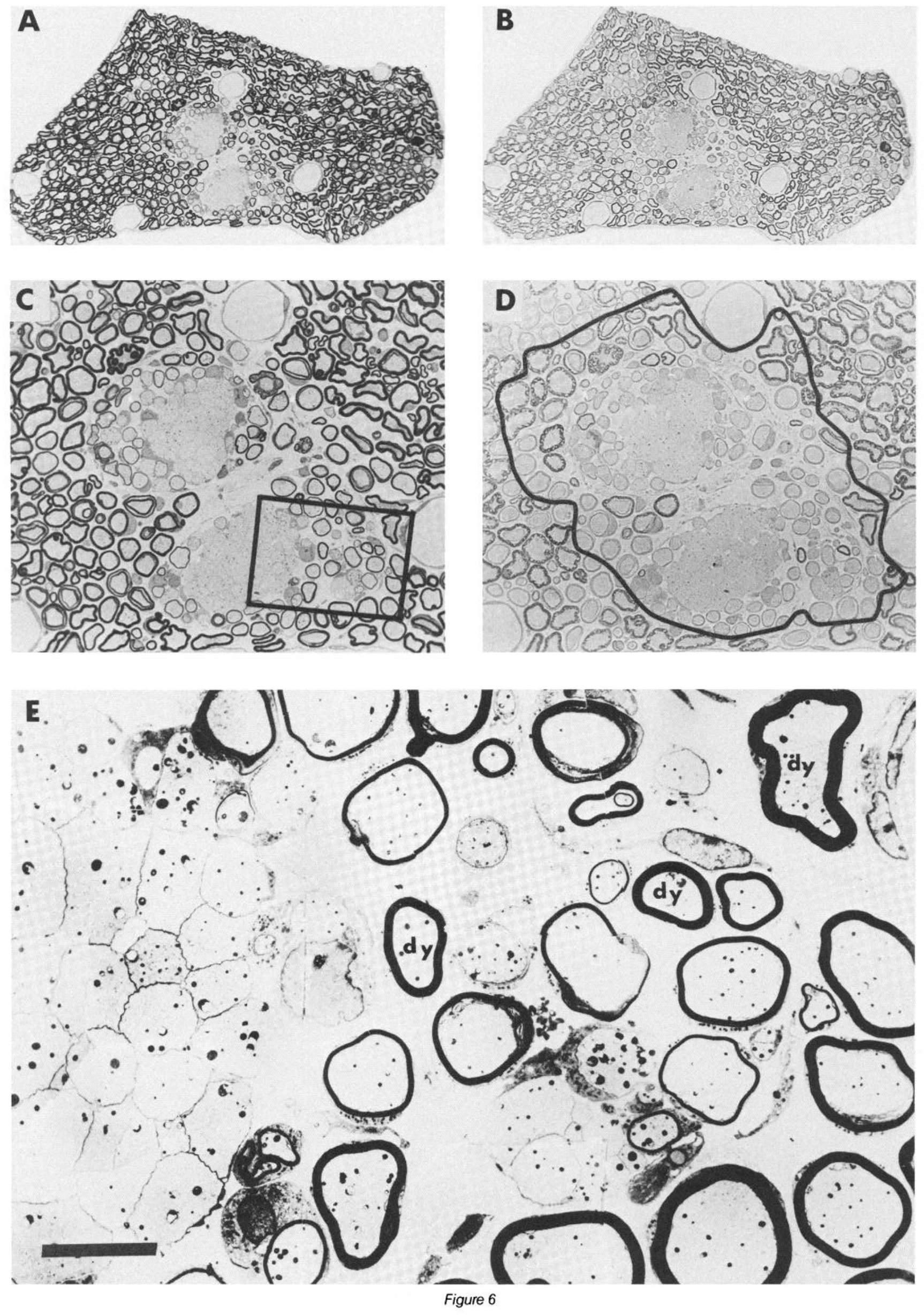
A.

Naked Axons

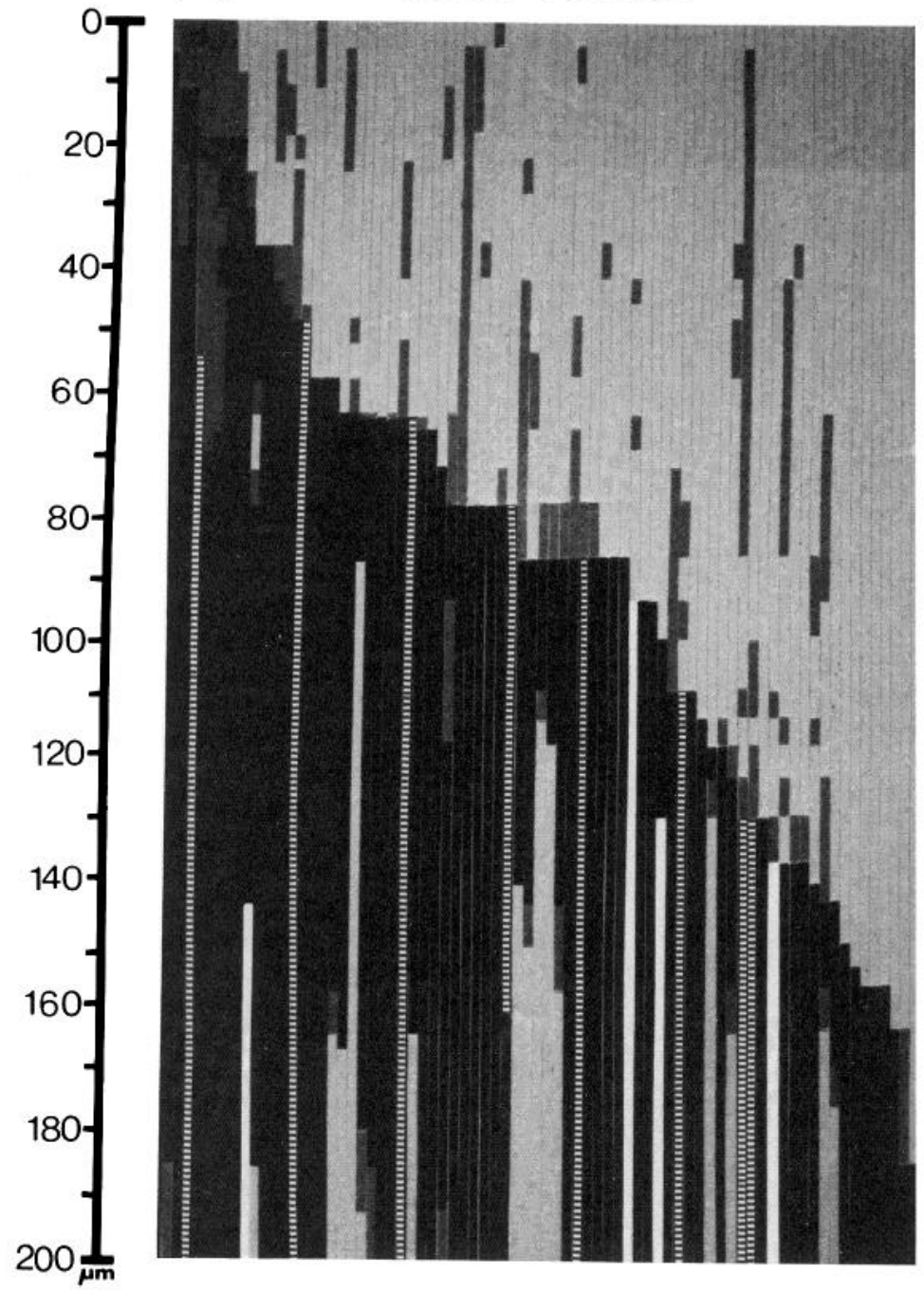

B.

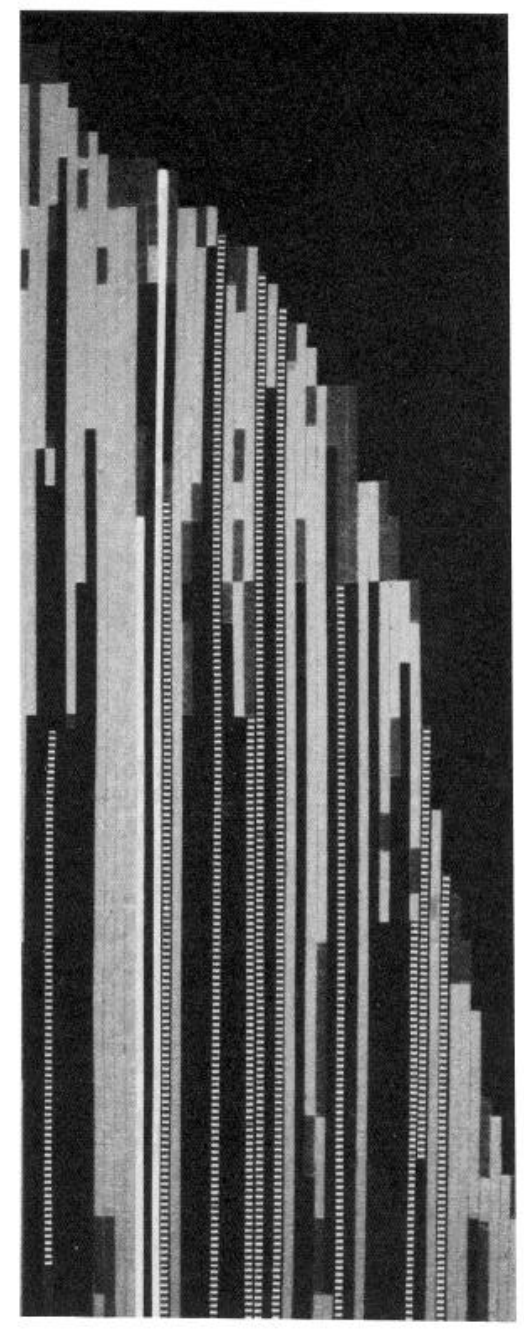

C. Dy

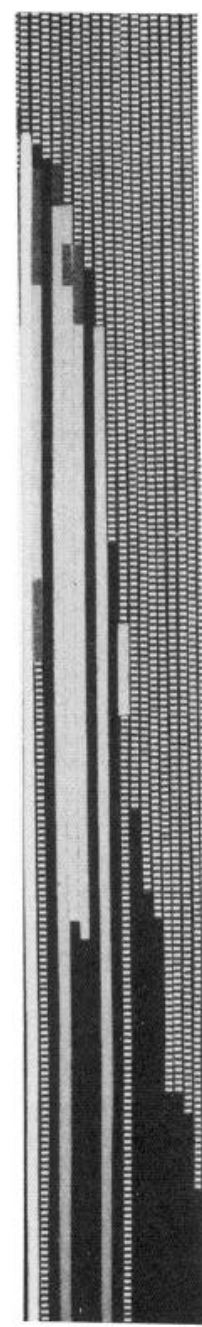

Figure 7. Longitudinal distribution of ensheathment changes determined for 300 fibers by reconstruction of skip serial sections traversing $200 \mu \mathrm{m}$ of the left L4V spinal root of chimera A. Fibers originating without ensheathment $(A)$, with shiverer myelin $(B)$, and with dystrophic myelin $(C)$ at the most proximal level of the reconstruction are presented separately. Only those fibers demonstrating ensheathment changes are included in the figure. The left-to-right ranking of the fibers indicates only the relative proximity of the first ensheathment change (involving a myelinated region) to the most proximal level of the reconstruction. All possible combinations of ensheathment changes were encountered throughout this $200-\mu \mathrm{m}$ segment. Black fibers, shiverer myelin; crosshatched fibers, dystrophic myelin; light gray fibers, naked axons; dark gray fibers, cytoplasmic processes associated with axon; white areas, axon no longer observed.

between the myelinated region of the fiber and the naked axon. Such a cytoplasmic process presumably emanated from uncommitted Schwann cells in the area, and, therefore, it remained possible that no myelinated Schwann cells were immediately adjacent to completely unensheathed axons. As there is no means of determining the genotype of these unmyelinated, presumptive Schwann cells, it remains unknown whether the cells giving rise to these cytoplasmic processes were of dystrophic or shiverer genotype.

To define more precisely the longitudinal relationships existing between naked axons and the shiverer or dystrophic Schwann cells, serial longitudinal sections from the right $L 4 V$ root of chimera $A$ were examined (Fig. 8). This analysis revealed further examples of heminodes ensheathed by Schwann cells of both genotypes. Moreover, naked axon segments apparently terminating directly at the myelinated Schwann cells were observed. If cytoplasmic processes emanating from additional cells were present, they either failed to completely surround the axon or they were not resolvable by light microscopy. Thus, no unique spatial distribution among the laterally or longitudinally oriented dystrophic Schwann cell populations is evident within these affected roots - a result that appears to defy implication of only the Schwann cell genotype in the primary pathogenesis of the naked axon phenotype.

The dystrophic neuropathy is also characterized by subtle, more generalized abnormalities of ensheathment in nerves in which all axons have been successfully isolated by glia during primary development. If this aspect of the dystrophic neuropathy were to arise exclusively in response to a Schwann cell abnormality, then it should also be observed in chimera nerves containing dystrophic Schwann cells. Cross-sections were examined for the presence of isolated, abnormally ensheathed axons. Several examples of such fibers were observed, and serial cross-sections revealed that, at the first myelinated heminodes, Schwann cells of either genotype could be present (Fig. 9). Thus, the ensheathment abnormalities expressed on axons, apparently separated appropriately during primary development, also fail to be strictly correlated with the genotype of the Schwann cells immediately bordering these sites.

\section{Discussion}

The quantitative portion of this study has revealed that no consistent developmental advantage is realized by Schwann cells of 
TABLE ॥

Summary of ensheathment characteristics of 300 fibers followed for 200 $\mu m$ in the left $L 4 V$ of chimera $A$

All possible combinations of ensheathment changes were observed but not at the same frequency. In particular, 91\% (107 of 118) of heminodes adjacent to naked or partially ensheathed axon segments involved shiverer Schwann cells.

\begin{tabular}{cc}
\hline Ensheathment Characteristic & No. and Percentage \\
\hline Fibers naked throughout & $75(25.0 \%)$ \\
Fibers myelinated throughout & $101(33.6 \%)$ \\
$S m^{a}$ & $54(18.0 \%)$ \\
$D m$ & $31(10.3 \%)$ \\
$S m \rightarrow D m$ & $7(2.3 \%)$ \\
$D m \rightarrow S m$ & $9(3.0 \%)$ \\
Fibers with ensheathment & $118(39.4 \%)$ \\
changes & \\
$S m \rightarrow n$ & $17(5.7 \%)$ \\
$D m \rightarrow n$ & $4(1.3 \%)$ \\
$n \rightarrow S m$ & $41(13.7 \%)$ \\
$n \rightarrow D m$ & $5(1.7 \%)$ \\
$S m \rightarrow n \rightarrow D m$ & $5(1.7 \%)$ \\
$S m \rightarrow n \rightarrow S m$ & $22(7.3 \%)$ \\
$D m \rightarrow n \rightarrow S m$ & $4(1.3 \%)$ \\
$n \rightarrow S m \rightarrow D m$ & $1(0.3 \%)$ \\
$n \rightarrow D m \rightarrow S m$ & $2(0.7 \%)$ \\
$n \rightarrow S m \rightarrow n$ & $17(5.7 \%)$ \\
$A x o n s$ terminating & $6(2.0 \%)$ \\
$S m \rightarrow 0$ & $1(0.3 \%)$ \\
$S m \rightarrow n \rightarrow 0$ & $2(0.7 \%)$ \\
$n \rightarrow 0$ & $3(1.0 \%)$ \\
\hline
\end{tabular}

${ }^{a}$ Sm, Shiverer myelin; Dm, dystrophic myelin; n, naked axons; o, axon terminates; $\rightarrow$, change of ensheathment.

either the shiverer or dystrophic genotype in chimera spinal roots. If either dystrophic Schwann cell progenitors were missing or specific clones had failed to proliferate and appropriately segregate and ensheath the axons in susceptible roots, a numerical compensation by the coexisting shiverer clones was predicted. Whereas two shil shi $\leftrightarrow d y^{2 t} / d y^{2 t}$ chimeras (B and C) did have a preponderance of shiverer Schwann cells in susceptible spinal roots, the other (chimera A) had roots dominated by the dystrophic Schwann cell population. These results suggest that the random selection of the progenitor Schwann cells originaliy allocated to each nerve accounts for these quantitative differences rather than any later perturbation in the relative developmental competence of one cell line. Moreover, the naked axons in the spinal roots of dystrophic mice are usually arranged in large groups, and no indication of relatively larger domains of shiverer cells was evident, a result anticipated if shiverer cells had "filled in" the axonal territories not occupied due to a developmental failure of dystrophic Schwann cells. Although the patterns of Schwann cell mosaicism observed in both shiverer $\leftrightarrow$ normal (Peterson and Marler, 1983) and Trembler $\leftrightarrow$ normal (Rayburn et al., 1980; Rayburn, 1983) chimera nerves are varied and frequently complex, no striking patterns of mosaicism appear to differentiate the Schwann cell distribution patterns in shi/shi $\leftrightarrow d y^{2 J} /$ $d y^{2 \jmath}$ nerves from those observed in either of the above two cases in which dystrophic cells are not present.

In the one chimera in which small groups of naked axons were observed, no indication of any special distribution of dystrophic Schwann cells in these roots was found. Rather, Schwann cells of both genotypes were found adjacent to naked axons in crosssections, and examples of both shiverer and dystrophic heminodes were observed both in the reconstruction study and in longitudinal preparations. Similar results were observed for abnormally ensheathed but individually segregated axons. However, in the serial cross-section study, $91 \%$ (107 of 118) of the fibers that changed from naked or partially ensheathed to myelinated did so at a shiverer heminode. This result may indicate that shiverer Schwann cells were selectively recruited to this region and partially succeeded in ensheathing previously naked axon segments. Alternatively, the Schwann cell population deployed to this site during primary development may have been similarly dominated by cells of shiverer genotype. In either case, in the immediate vicinity of myelinated shiverer Schwann cells, naked axon segments persisted in these chimera roots. Thus, the combined quantitative and qualitative results indicate that the genotype of the Schwann cell populations in chimera roots does not correlate with the developmental expression of the naked axon phenotype. Moreover, the presence of shiverer Schwann cells in affected roots is not of itself adequate to correct this abnormality. Shiverer Schwann cells are competent to ensheath regenerating nerves in transplant experiments $(R$. L. Sidman, personal communication), but their presence within the two affected roots, presumably during the entire lifetime of the mature chimeras, and their apparently ideal location did not lead to the effective repair of the primary development failure.

Uncommitted, presumably undifferentiated Schwann cells continuously undergoing mitotic division is another striking feature of dystrophic spinal roots (Perkins et al., 1980). Such undifferentiated cells were also observed in the affected spinal roots of chimera A. If the primary genetic defect underlying the dystrophic ensheathment abnormality were expressed exclusively by some cell type other than the Schwann cell itself, the presumptive uncommitted Schwann cells in the chimera could be either shiverer or dystrophic. However, as no means of identifying the genotype of such uncommitted cells in Epon-embedded nerves is known, it remains possible that, within the affected chimera roots, all presumptive uncommitted Schwann cells are genotypically dystrophic. Theoretically, the particular distribution of their cytoplasmic processes could interfere with the normal developmental or regenerative capabilities of the shiverer Schwann cell population. However, Schwann cell division in primary development is associated with retraction of cytoplasmic processes (Webster, et al., 1973; Webster, 1975), and if the uncommitted Schwann cells in the chimera nerves similarly continued to divide, any physical barrier preventing competent Schwann cells from proliferating and invading naked axon bundles would be a transitory phenomenon. Furthermore, the localized ensheathment abnormalities present on isolated axons indicates that other physical barriers, such as direct adhesion between naked axons, cannot account for the ensheathment abnormalities observed. Thus, the origoing block to successful axon separation and ensheathment that exists in dystrophic spinal roots appears to be reiterated in the chimera roots without regard to the genotype or location of those myelinated Schwann cells populating the remainder of the root. A pathogenetic mechanism involving more than the genotype of the dystrophic Schwann cell is therefore suggested by these findings.

The dystrophic or shiverer genotype of the neurons sending axons through the chimera spinal roots is unknown; therefore, the role, if any, of the dystrophic neuron in the ensheathment defect could not be directly assessed in the present investigation. Nonetheless, the extent of the abnormalities observed in these chimeras is not consistent with that predicted if an axonal defect were responsible. In particular, the maximal expression of the ensheathment failure expressed in dystrophic mice is typically found in the middle of the longer spinal roots; a greater proportion of the axons are typically ensheathed in both the more proximal and distal regions of the root (Stirling, 1975). However, in the affected right L4V root of chimera $A$, naked axons were observed only in the most distal segment; some additional restriction in the longitudinal susceptibility to ensheathment failure independent of the continuous axon population is therefore indicated. Moreover, Schwann cells, melanocytes, and dorsal root ganglion neurons are all neural crest derivatives, and as both the pigmentation of these chimeras and the Schwann cell populations in every root contained derivatives of both shiverer and dystrophic cells, the neurons populating dorsal root ganglia might also originate from progenitors of both genotypes. However, no 


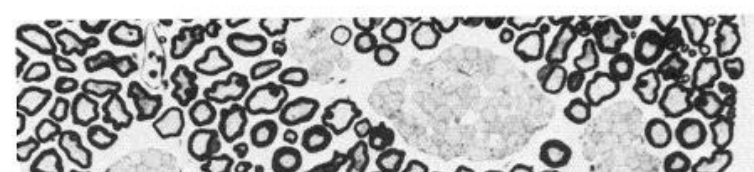

प. 03090000

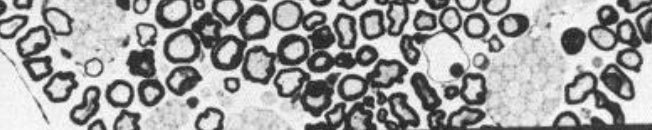
-

B

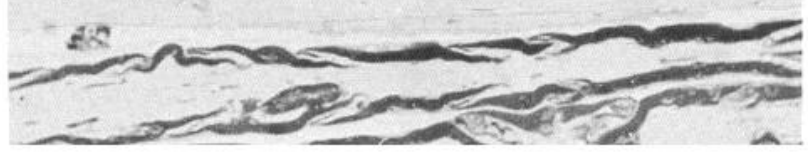

C

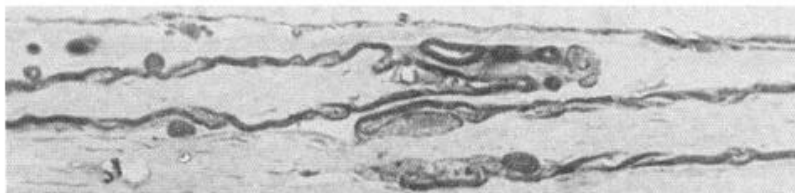

D
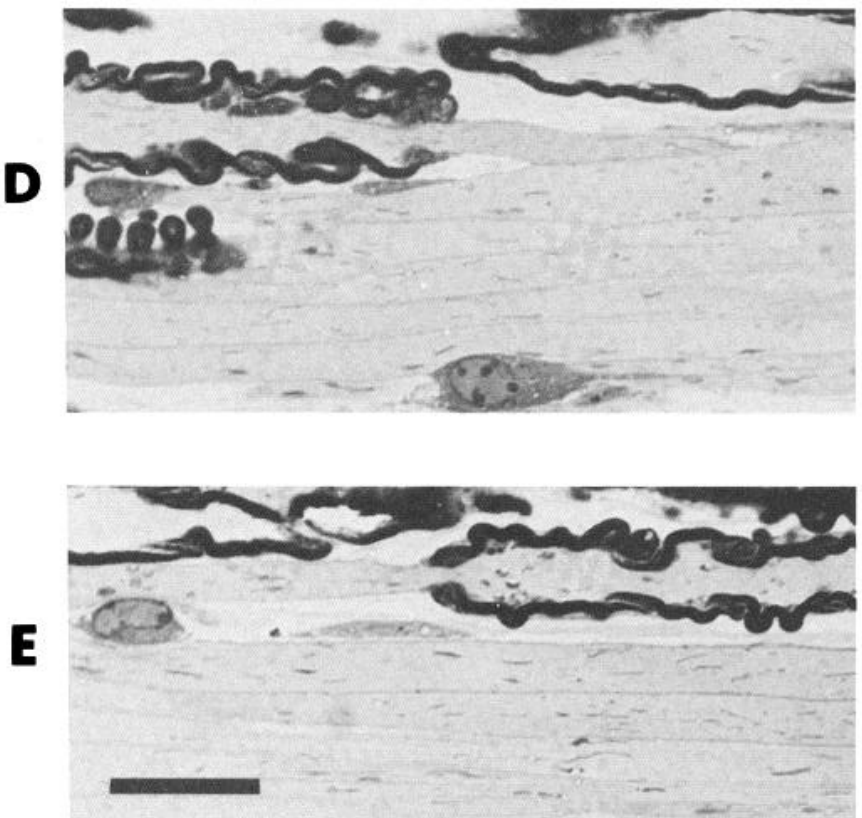

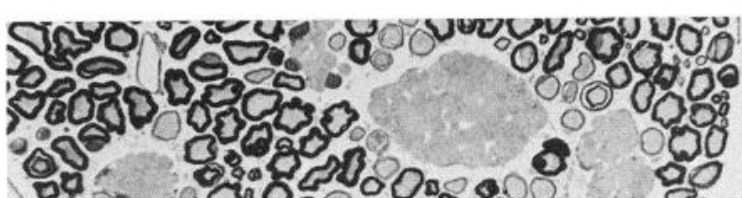

o, 00800000000 D $3,0000.030$. - 0000000

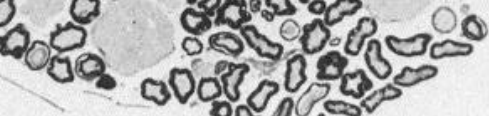
क्ल०
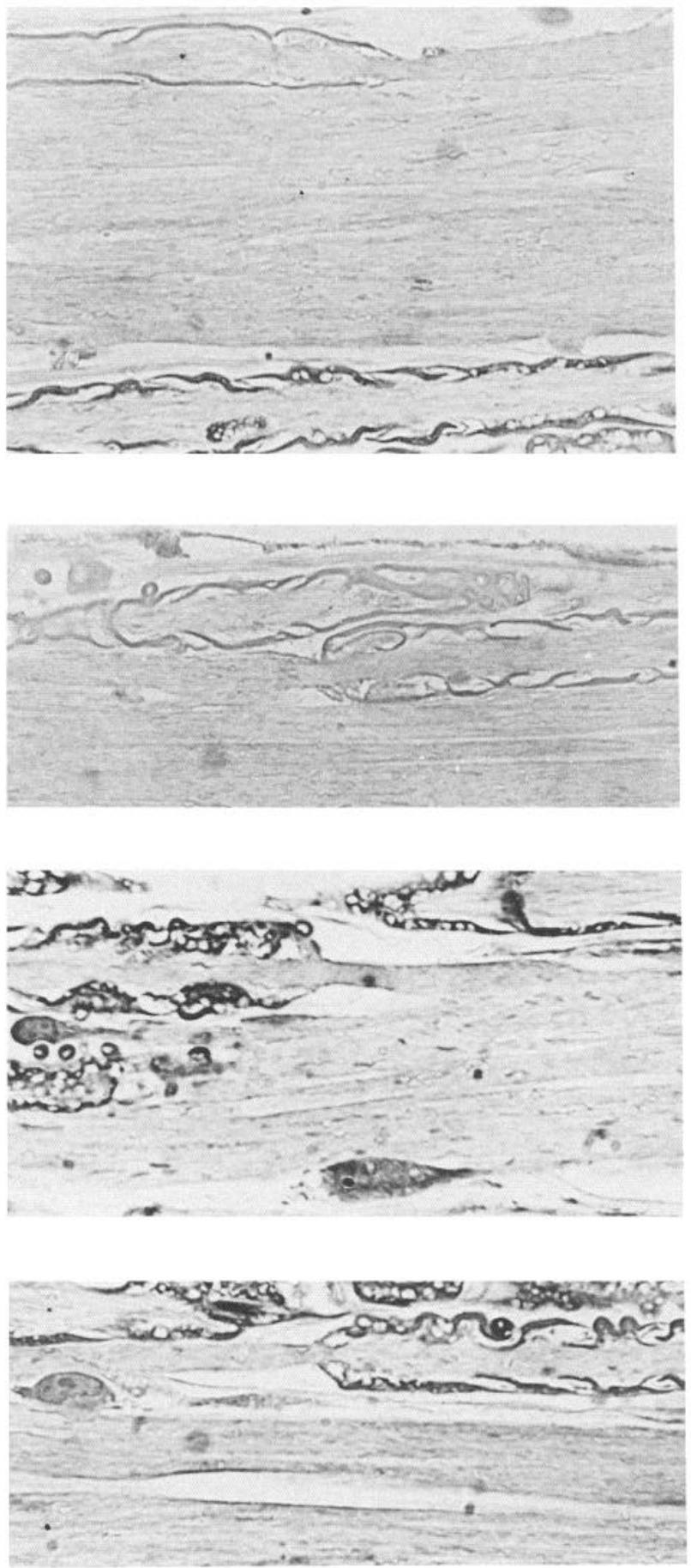
gross ensheathment defects in any of the chimera dorsal root samples were detected, leading to the conclusion that either a mosaic axon population did not exist in these sites, or, more likely, dystrophic axons were present, but the axon genotype is not of significance.

The relatively small size and location and the restricted distribution of the naked axon bundles observed in these chimeras demonstrates that the in vivo expression of the dystrophic ensheathment abnormality is not an all-or-none phenomenon either at the single root level or for the mouse. Nonetheless, the L $4 \mathrm{~V}$ roots of dystrophic mice are severely affected, with only a very small proportion of the axons typically ensheathed at the midroot level; it is therefore striking that within these chimeras, the only grossly affected nerves were $\mathrm{L} 4 \mathrm{~V}$ roots. This apparent correlation suggests that the local environment in such roots may be a particularly relevant feature of the pathogenesis. This circumstance further suggests that the axon genotype is not involved, as there is no a priori reason to predict that motor neurons would be segregated during development such that only the $L 4 V$ roots of one chimera would contain axons originating from dystrophic cells. Moreover, the absolute length of the spinal root is not indicated as a factor related closely to the primary pathogenetic mechanism as the $L 4 D$ roots in chimera $A$ were not similarly affected.

Several in vitro experiments have indicated that the realization of normal extracellular matrix is a prerequisite of normal axon-Schwann cell interaction (Bunge et al., 1982; Cornbrooks et al., 1983). The general amelioration of the dystrophic ensheathment deficiency in chimera nerves should therefore indicate an improved ability of the dystrophic Schwann cells to elaborate intact basal laminas. In a quantitative ultrastructural study, the basal lamina phenotype expressed by the myelinated Schwann cells in these chimera nerves has been determined (Peterson and Bray, 1984b); and as predicted by this hypothesis, ultrastructurally normal basal laminas were expressed on all Schwann cells examined, regardless of their genotype or particular location within the chimera PNS.

The normalized phenotype expressed by dystrophic Schwann cells in the chimera nerves must be achieved by an extracellularly mediated influence emanating from the shi/shi cells coexisting within these mice. Some unknown type of shiverer cell must either provide the normal gene product directly to the dystrophic Schwann cells or serve to remove a primary extra Schwann cell abnormality. Although the source and nature of this normalizing influence have not been identiried, the present results indicate that neither the axons nor the shiverer Schwann cells are involved. However, an intriguing possibility has been advanced by Bunge et al. (1980), who have exploited an elegant tissue culture system in which pure populations of neurites, Schwann cells, and fibroblasts from both dystrophic and normal mice can be co-cultured in various combinations. In cocultures of normal neurites and Schwann cells, axons become typically ensheathed by Schwann cells that subsequently produce myelin and elaborate intact basal laminas. However, in comparable dystrophic co-cultures, some of the more subtle neurological deficiencies expressed in the dystrophic PNS are reiterated, including inappropriately long nodes of Ranvier and patchy basal laminas. These deficiencies are not corrected in co-cultures where dystrophic Schwann cells are innervated by normal neurons, and they are not expressed by normal Schwann cells innervated by dystrophic neurites. Thus, in contrast to the present findings, a deficiency expressed within the dystrophic Schwann cell itself appears to be defined. However, if normal fibroblasts are added to co-cultures of nerves and Schwann cells obtained from dystrophic mice, the
Schwann cell basal lamina deficiencies are eventually ameliorated. On the basis of this result, a hypothesis implicating a primary genetic defect expressed within the endoneurial fibroblasts in dystrophic mice was advanced (Bunge et al., 1982; Cornbrooks et al., 1983). In support of this possibility, there is a naturally occurring paucity of endoneurial fibroblasts in the spinal roots of normal mice, and a parallel difference exists in the endoneurial collagen content of roots and sciatic nerves (Micko and Schlaepfer, 1979). Thus, a direct relationship between those sites typically expressing the lowest density of endoneurial fibroblasts and the maximal expression of the dystrophic ensheathment defect is suggested. In addition, for Schwann cells to effectively recognize and ensheath axons in vitro, they must contact both the axon and a collagen-containing substrate (Bunge and Bunge, 1978).

The seemingly conflicting results from the in vitro experiments that implicate both a primary Schwann cell defect and a primary fibroblast defect are reconcilable by the suggestion that molecules secreted by normal fibroblasts may substitute for an intrinsic deficiency of dystrophic Schwann cells (Bunge et al., 1982; Cornbrooks et al., 1983). Ths hypothesis suggests that the dystrophic Schwann cell population can overcome an intrinsic deficiency by sharing a gene product secreted by genotypically normal fibroblasts. Of particular interest, dystrophic fibroblasts may not be totally deficient in their ability to confer such an influence. First, in dystrophic mice, the distribution of major ensheathment defects is restricted to only those sites in which endoneurial fibroblasts are rare. Second, both the spinal root ensheathment and Schwann cell basal lamina deficiencies are substantially ameliorated in nerves that have regenerated in response to local crush injury, and such regenerated nerves contain higher concentrations of collagen (Bray et al., 1983) and an increased density of endoneurial fibroblasts (Thomas, 1975). Third, dystrophic Schwann cells maintained in pure Schwann cell neurite co-cultures have more severe basal lamina deficiencies than do those maintained in the additional presence of dystrophic fibroblasts (Okada et al., 1980; Bunge et al., 1982; Cornbrooks et al., 1983). Thus, the dystrophic fibroblast appears to maintain at least partial ability to promote normal Schwann cell axon interactions both in vivo and in vitro.

The present results do not exclude a pathogenetic mechanism defined as a deficiency shared by dystrophic Schwann cells and fibroblasts. In chimera spinal roots demonstrating normal ensheathment, the dystrophic Schwann cells at those sites could achieve their normalized ensheathment capabilities in direct response to the local presence of shiverer endoneurial fibroblasts. However, to be consistent with the chimera findings, this hypothesis must be extended. In affected chimera roots, both dystrophic and shiverer Schwann cells failed to ensheath naked axons. If a local paucity of shiverer fibroblasts were responsible for this ensheathment failure, that deficiency not only would fail to rescue the dystrophic Schwann cells but would also inhibit the normal developmental and/or regenerative potential of the shiverer Schwann cells. Thus, normal endoneurial fibroblast function as a prerequisite of successful axon Schwann cell interaction in vivo is suggested. Although this apparent in vivo requirement is not revealed by the successful axon ensheathment observed in co-cultures containing only Schwann cells and neurons, the in vivo role indicated for endoneurial fibroblasts may be conferred in culture by factors already present in the culture media. In support of this possibility, normal Schwann cells, although capable of division in chemically defined media, do not ensheath the neurites they contact (Moya et al., 1980). Thus, in the dystrophic mouse, the Schwann cells populating spinal roots may fail to en-

Figure 8. Genotype of Schwann cells at myelinated heminodes immediately adjacent to unensheathed axon segments. Sections stained with toluidine blue are presented on the left and the adjacent sections, stained by P1 immunocytochemistry, are presented on the right. A, Scrial cross-scctions of the distal segment of the chimera A right L4V root. Although dystrophic Schwann cells (P1 positive) are most prevalent in this affected region of the root, some fibers ensheathed by shiverer ( $P 1$ negative) Schwann cells are found adjacent to naked axons. The block was realigned, and serial longitudinal sections, in a sequence of $0.5 \mu \mathrm{m}$ for toluidine blue and $2.0 \mu \mathrm{m}$ for $\mathrm{P} 1$ immunocytochemistry, were cut parallel to the axis indicated in $A$. Examples of shiverer heminodes are presented in $B$ and $C$, and examples of dystrophic heminodes are shown in $D$ and $E$. 

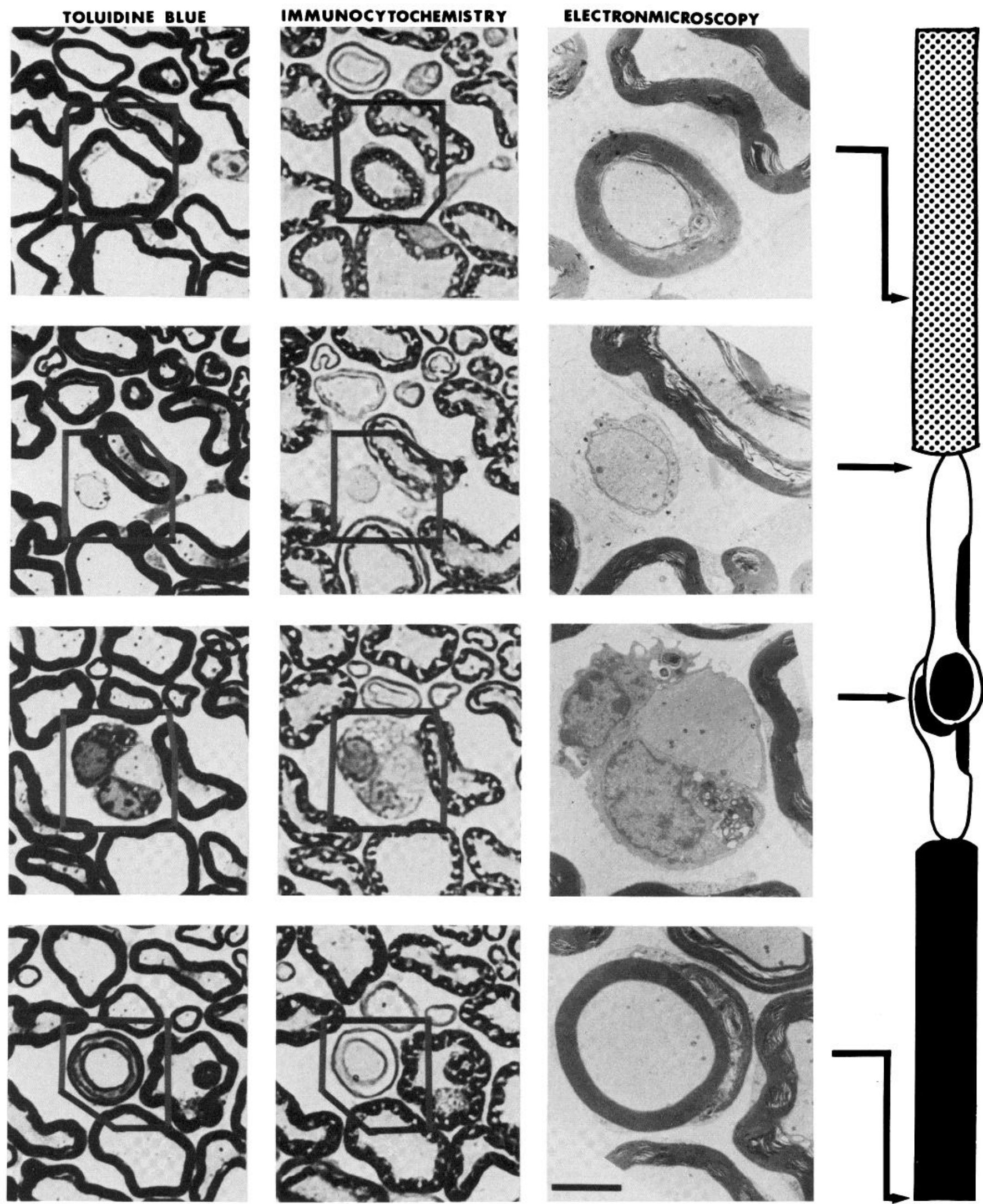

Figure 9. Reconstruction of $222 \mu \mathrm{m}$ of an abnormal ensheathed single fiber surrounded by normally ensheathed axons. At the proximal level this fiber was myelinated by a dystrophic Schwann cell (indicated by stippled myelin on the diagram). The processes of two cells either partially or completely surround the axon for $38 \mu \mathrm{m}$ in the middle segment. The fiber again became myelinated in the most distal segment but by a shiverer Schwann cell (indicated in black). 
sheath axons only as a consequence of the localized extra Schwann cell deficiency existing at those sites. In the chimeras where this same deficiency exists due to the combined site-specific paucity of fibroblasts and the intrinsic deficiency of the dystrophic fibroblasts populating those sites, neither dystrophic nor shiverer Schwann cells express normal ensheathment characteristics.

The severe expression of ensheathment defects in dystrophic $L 4 \mathrm{~V}$ roots and the occurrence of similar defects within only the $L 4 \mathrm{~V}$ roots of one chimera further suggest that L $4 \mathrm{~V}$ roots may normally contain a fibroblast density very close to the minimum required to confer an adequate substrate for ensheathment to proceed. Thus, an approximately equivalent proportion of dystrophic and shiverer fibroblasts could exist in all spinal roots of chimera $A$, but the absolute number of shiverer Schwann cells would fall below the threshold required to promote normal ensheathment only within the $L 4 \mathrm{~V}$ roots. The laterally and longitudinally restricted distribution of the naked axons groups observed in the affected chimera roots suggests that such an extracellular influence is effective only in close proximity to its origin.

The results of previous chimera experiments addressing the role of the muscle genotype in the pathogenesis of the muscle disease in dystrophic mice might also be consistent with some features of the pathogenetic mechanism suggested above for the dystrophic neuropathy. In particular, the genotype of the muscle fibers themselves does not correlate with the expression of a healthy or diseased phenotype defining an important role for some component extrinsic to the muscle fiber itself (Peterson et al., 1979). It is, therefore, possible that the muscle disease is also a response to some subtle perturbation in the immediate extracellular environment of the muscle fiber.

Finally, the mosaicism expressed in chimera peripheral nerves highlights one further feature of normal Schwann cell differentiation. All chimera nerves and spinal roots examined had mosaic Schwann cell populations, defining the presence of multiple Schwann cell progenitors for each nerve. If the smaller cross-sectional patches of Schwann cells of like genotype represent the clone of Schwann cells derived from single progenitors, then a relatively large population of such progenitors must populate each developing nerve. Consistent with this probability is the fact that all chimera nerves contain both Schwann cell types; if a very small number of progenitors is allocated to each nerve, the chance selection of cells of only one genotype should be a common occurrence.

\section{References}

Aguayo, A. J., G. M. Bray, and C. S. Perkins (1979a) Axon-Schwann cell relationships in neuropathies of mutant mice. Ann. N. Y. Acad. Sci. 317: 512-531.

Aguayo, A. J., G. M. Bray, C. S. Perkins, and I. D. Duncan (1979b) Axonsheath cell interactions in peripheral and central nervous system transplants. In Society for Neuroscience Symposia. Vol. 4: Aspects of Deve/opmental Neurobiology, pp. 361-383, Society for Neuroscience, Bethesda, MD

Asbury, A. J. (1967) Schwann cell proliferation in developing mouse sciatic nerve. J. Cell Biol. 34: 735-743.

Ayers, M. M., and R. M. Anderson (1973) Onion bulb neuropathy in the Trembler mouse: A model of hypertrophic interstitial neuropathy (DejerineSottas) in man. Acta Neuropathol. 25: 54-70.

Ayers, M. M., and R. M. Anderson (1976) Development of onion bulb neuropathy in the Trembler mouse. Acta Neuropathol. 36: 137-152.

Bostock, H., and T. A. Sears (1978) The internodal axon membrane: Electrical excitability and continuous conduction in segmental demyelination. I Physiol. (Lond.) 280: 273-301.

Bradley, W. J., and M. Jenkison (1973) Abnormalities of peripheral nerves in murine muscular dystrophy. J. Neurol. Sci. 18: 227-247.

Bradley, W. J., and M. Jenkison (1975) Neural abnormalities in the dystrophic mouse. J. Neurol. Sci. 25: 249-255.

Bray, G., S. Perkins, A. C. Peterson, and A. J. Aguayo (1977) Schwann cell multiplication deficit in nerve roots of new born dystrophic mice. J. Neurol. Sci. 32: 203-212.

Bray, G. M., M. Rasminsky, and A. J. Aguayo (1981) Interactions between axons and their sheath cells. Annu. Rev. Neurosci. 4: 127-162.
Bray, G. M., S. David, T. Carlstedt, and A. J. Aguayo (1983) Effects of crush injury on the abnormalities in the spinal roots and peripheral nerves of dystrophic mice. Muscle Nerve 6: 497-503.

Bunge, M. G., A. K. Williams, P. M. Wood, J. Uitto, and J. J. Jeffrey (1980) Comparison of nerve cell and nerve cell plus Schwann cell cultures with particular emphasis on basal lamina and collagen formation. J. Cell Biol. 84: 184-202.

Bunge, R. P., and M. B. Bunge (1978) Evidence that contact with connective tissue matrix is required for normal interaction between Schwann cells and nerve fibers. J. Cell Biol. 78: 943-950.

Bunge, R. P., M. B. Bunge, A. K. Williams, and L. K. Wartels (1982) Does the dystrophic mouse nerve lesion result from an extracellular matrix abnormality? In Disorders of the Motor Unit, D. L. Schotland, ed., pp. 2335, John Wiley \& Sons, New York.

Butler, J., and E. Cosmos (1977) Histochemical and structural analyses of the phenotypic expression of the dystrophic gene in the 129/ReJ $d y / d y$ and the C57BL/6J dy2J/dy2J mice. Exp. Neurol. 57: 666-681.

Chernoff, G. F. (1981) Shiverer: An autosomal recessive mutant mouse with myelin deficiency. J. Hered. 72: 128.

Cornbrooks, C., M. Cochran, F. Mithen, M. B. Bunge, and R. P. Bunge (1980) Myelination in explants of Trembler dorsal root ganglion grown in culture. Trans. Am. Soc. Neurochem. 11: 110.

Cornbrooks, C. J., F. Mithen, J. M. Cochran and R. P. Bunge (1983) Factors affecting Schwann cell basal lamina formation in cultures of dorsal root ganglia from mice with muscular dystrophy. Dev. Brain Res. 6: 57-67.

Ganser, A. L., and D. L. Kirschner (1979) Abnormal myelin in peripheral nerve of the shiverer mouse. Trans. Am. Soc. Neurochem. 10: 177.

Jaros, E., and W. G. Bradley (1979) Atypical axon-Schwann cell relationships in the common peroneal nerve of the dystrophic mouse: An ultrastructural study. Neuropathol. Appl. Neurobiol. 5: 133-147.

Kirschner, O. A., and A. L. Ganser (1980) Compact myelin exists in the absence of basic protein in the shiverer mutant mouse. Nature 283: 207210.

Low, P. A. (1977) The evolution of "onion bulbs" in hereditary hypertrophic neuropathy of the Trembler mouse. Neuropathol. Appl. Neurobiol. 3: 8192.

Madrid, R. E., E. Jaros, M. J. Cullen, and W. G. Bradlcy (1975) Genetically determined defect of Schwann cell basement membrane in dystrophic mouse. Nature 257: 319-321.

Michelson, A., E. Russell, and P. Harman (1955) Dystrophia muscularis: A hereditary primary myopathy in the house mouse. Proc. Natl. Acad. Sci. U. S. A. 41: 1079-1084.

Micko, S., and W. W. Schlaepfer (1979) Proximo-distal gradient of endoneurial collagen in rat peripheral nerves. J. Neurochem. 32: 221-223.

Moya, F., M. B. Bunge, and R. P. Bunge (1980) Schwann cells proliferate but fail to differentiate in defined medium. Proc. Natl. Acad. Sci. U. S. A. 77: $6902-6906$

Mullen, R. J., and W. K. Whitten (1971) Rclationship of genotype and degree of chimerism in coat color to sex ratios and gametogenesis in chimaeric mice. J. Exp. Zool. 178: 165-176.

Okada, E., R. P. Bunge, and M. B. Bunge (1980) Abnormalities expressed in long term cultures of dorsal root ganglia from the dystrophic mouse. Brain Res. 194: 455-470.

Perkins, C. S., G. M. Bray, and A. J. Aguayo (1980) Evidence for undifferentiated Schwann cells in the spinal roots of dystrophic mice. Can. J. Neurol. Sci. 7: 123.

Peters, A., and A. R. Muir (1959) The relationship between axons and Schwann cells during development of peripheral nerves in the rat. Q. $J$ Exp. Physiol. 44: 117-130.

Peterson, A., and G. Bray (1984a) Hypomyelination in the peripheral nervous system of shiverer mice and in shiverer $\leftrightarrow$ normal chimaera. J. Comp. Neurol. 227: 348-356.

Peterson, A., and G. Bray (1984b) Normal basal laminas are realized on dystrophic Schwann cells in dystrophic $\leftrightarrow$ shiverer chimaera nerves. J. Cell Biol. 99: 1831-1837.

Peterson, A., and J. Marler (1983) P1 deficiency in shiverer myelin is expressed by Schwann cells in shiverer $\leftrightarrow$ normal mouse chimaera nerves Neurosci. Lett. 38: 163-168.

Peterson, A. C., P. M. Frair, and G. G. Wong (1978) A technique for detection and relative quantitative analysis of glucosephosphate isomerase isozymes from nanogram tissue samples. Biochem. Genet. 16: 681-690.

Peterson, A. C., P. M. Frair, H. R. Rayburn and D. P. Cross (1979) Development and disease in the neuromuscular system of muscular dystrophic $\leftrightarrow$ normal mouse chimaeras. In Society for Neuroscience Symposia. Vol. 4: 
Aspects of Developmental Neurobiology, pp. 258-273, Society for Neuroscience, Bethesda, MD.

Raine, C. S., H. Wisniewski, and J. Prineas (1969) An ultrastructural study of experimental demyelination and remyelination. II. Chronic experimental allergic encephalomyelitis in the peripheral nervous system. Lab. Invest 21: 316-327.

Rayburn, H. R. (1983) The development of Schwann cell clones in the mammalian peripheral nervous system: A study using Trembler $\leftrightarrow$ normal mouse chimaeras. Ph.D. thesis, McMaster University, Hamilton.

Rayburn, H. R., A. C. Peterson, and A. J. Aguayo (1980) Development and deployment of Schwann cells in peripheral nerves of trembler $\leftrightarrow$ norma mouse chimaeras. Soc. Neurosci. Abstr. 6: 660.

Roach, A., K. Boylan, S. Horvath, S. Prusiner, and L. Hood (1983) Characterization of cloned cDNA representing rat myelin basic protein: Absence of expression in brain of shiverer mutant mice. Cell 34: 799-806.

Rosenbluth, J. (1980) Peripheral myelin in the mouse mutant shiverer. J. Comp. Neurol. 193: 729-739.

Sternberger, L. A., P. H. Hardy, J. J. Cuculis, and H. G. Meyer (1970) The unlabelled antibody enzyme method of immunocytochemistry. J. Histochem. Cytochem. 18: 315-333.

Stirling, C. A. (1975) Abnormalities in Schwann cell sheaths in spinal nerve roots of dystrophic mice. J. Anat. 119: 169-180.

Suzuki, K., and J. C. Zagoren (1977) Quaking mouse: An ultrastructural study of the peripheral nerves. J. Neurocytol. 6: 71-84.

Thomas, P. K. (1975) Nerve injury. In Essays on the Nervous System, R. Bellairs and E. G. Gray, eds., pp. 44-70, Oxford University Press, London.

Trapp, B. D., Y. Itoyama, N. H. Sternberger, R. H. Quarles, and H. de F. Webster (1981) Immunocytochemical localization of Po protein in Golgi complex membranes and myelin of developing rat Schwann cells. J. Cell Biol. 90: 1-6.

Webster, H. de F. (1975) Development of peripheral myelinated and unmyc linated nerve fibers. In Peripheral Neuropathy, P. J. Dyck, E. Lambert, and P. K. Thomas, eds., pp. 37-61, W. B. Saunders Co., Philadelphia.

Webster, H. de F., J. R. Martin, and M. F. O'Connell (1973) The relationship between interphase Schwann cells and axons before myelination: A quantitative electron microscopic study. Dev. Biol. 32: 401-416. 